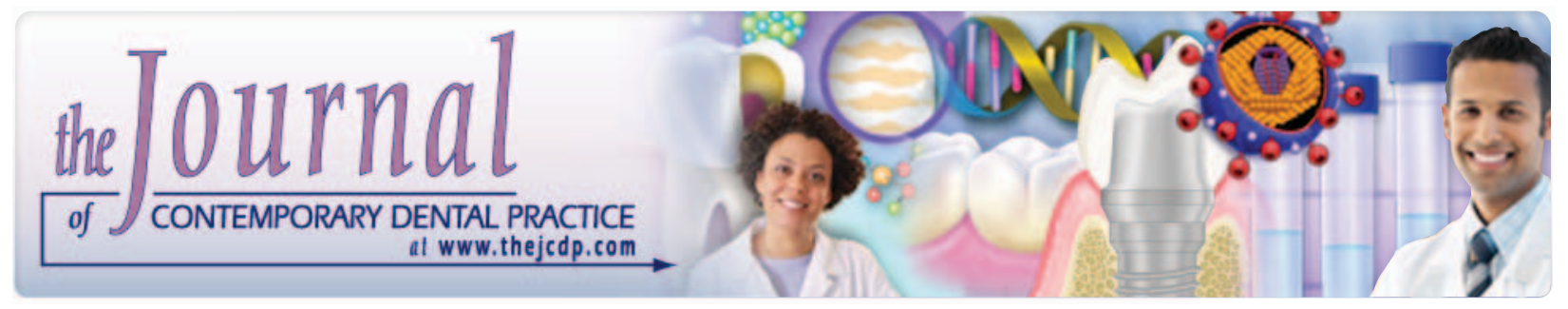

\title{
Management of Crowded Class 1 Malocclusion with Serial Extractions: Report of a Case
}

Hayder A. Hashim, BDS, MSc

\section{Abstract}

Aim: The purpose of this article is to show the value of serial extractions in a young patient with severe crowding.

Background: Serial extraction is a technique advocated for use by Kjellgren ${ }^{1}$ in 1948 due to a shortage of orthodontists at the time. This form of treatment was intended to facilitate the treatment of orthodontic cases by general dentists to minimize the demand upon the orthodontist.

Case Description: An eight-year-old Sudanese female did not like the appearance of her anterior teeth. Clinical examination revealed a Class I molar relationship, severe crowding of the maxillary and mandibular arches, minimum overjet, and minimum overbite.

Results: The patient's treatment included serial extractions. The treatment resulted in improved esthetics, good arch alignment, and occlusion while maintaining her Class I molar relationship, overjet, and overbite.

Summary: This case demonstrated that despite the criticism some may direct toward this interceptive technique, good clinical results can be achieved in carefully selected cases.

Clinical Significance: There are certain clinical situations when treatment planning the use of serial extractions can prove beneficial to young patients.

Keywords: Serial extractions, extractions, orthodontics, crowding

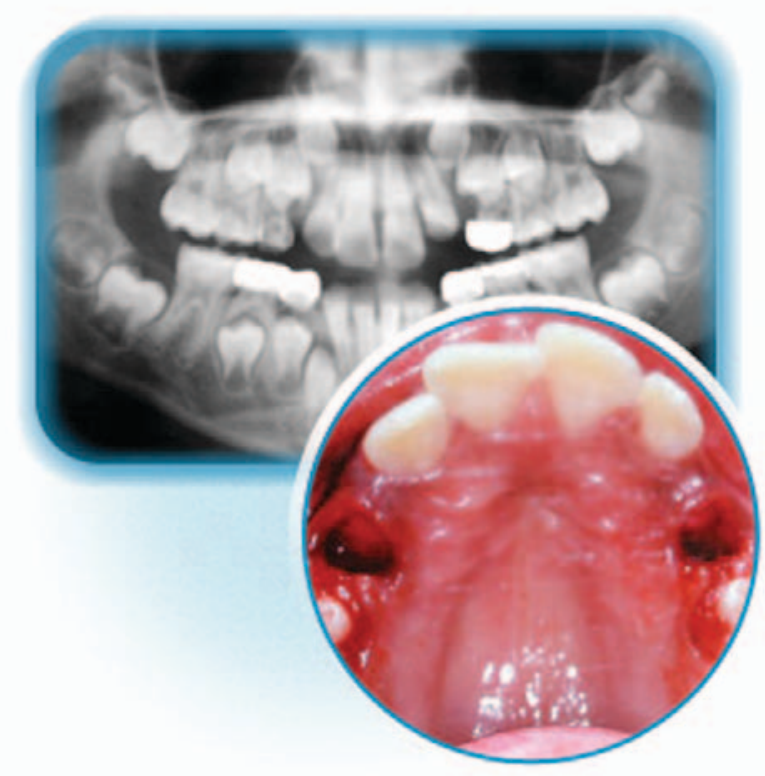

Citation: Hashim HA. Management of Crowded Class 1 Malocclusion with Serial Extractions: Report of a Case. J Contemp Dent Pract [Internet]. 2010 July; 11(4):041-048. Available from: http://www.thejcdp.com/journal/view/ volume11-issue4-hashim

\section{Introduction}

The most common orthodontic problem is poor alignment due to crowding of the teeth. If the extractions are performed early, there is a good chance malalignment of the teeth can be prevented.

Serial extraction is an interceptive procedure performed in the treatment of a severely mixed 
dentition with some crowding, by the orderly removal of selected deciduous and permanent teeth in a predetermined sequence. It is carried out at planned intervals as dictated by each individual case. ${ }^{1}$

Kjellgren $^{1}$ reportedly first advocated serial extractions in 1948 as a response to an apparent shortage of orthodontists. He hoped this procedure would facilitate the treatment of straightforward cases of crowding by their general dentist, thereby minimizing the demand upon the orthodontist.

Dewel ${ }^{2}$ stated: "The prudent course to follow in borderline cases, is first to attempt the correction without extraction. In this way, no child will be jeopardized by a precipitous program of serial extraction."

Hotz $^{3}$ referred to the procedure of serial extraction as guidance of eruption, or guidance of occlusion, because it implies that knowledge of growth and development is necessary to direct the teeth as they erupt into occlusion. He stated that the specialty must assume its responsibility for educating the predoctoral students in the science of guided eruption. With such basic knowledge, the general practitioner, under the supervision of an orthodontist, will be able to bring the benefits of orthodontics to more children.

Further, Yoshihara et al. ${ }^{4}$ noticed that spontaneous changes in a dentition after serial extraction might be useful for therapeutic purposes in the correction or reduction of crowding in most Class I cases. However, they recommended close follow-up after serial extraction. If needed, active orthodontic treatment should be initiated to establish a satisfactory occlusion.

In contrast, Dale ${ }^{5}$ stated that serial extraction is not as easy as so many mistakenly believe, and should never be initiated without a comprehensive diagnosis. If the basic principles of diagnosis are ignored, the result will be failure and disappointment. On the other hand, if serial extraction is based on a thorough diagnosis, performed carefully, and properly executed on selected patients, the procedure can offer an excellent and valuable treatment modality.

The ideal guidelines for serial extractions include absence of skeletal discrepancies, large arch- length deficiency (5-9 mm), normal overbite, Class I malocclusion, and a commitment on the practitioner's part to finishing the case. ${ }^{\underline{6}}$

The main goal of serial extraction is to increase the probability of creating a stable treatment outcome. But the treated positions may be more difficult to stabilize even with long-term retention. Therefore, it is much better to have the teeth erupt into relatively correct positions on their own, which serial extraction can allow, and thereby reduce fixed appliance treatment time in the future.

The aim of this article is to present a young patient with severe crowding managed with the serial extractions procedure that produced good results.

\section{Case Report}

An eight-year-old female Sudanese child presented to the Orthodontic Clinic at Rumaila Hospital stating that she did not like the appearance of her anterior teeth. Her medical history was negative. Her dental history included early extraction of the mandibular right and left deciduous canines. The patient's primary concern had to do with the appearance of her anterior teeth.

\section{Clinical Examination}

Extraoral examination revealed a convex profile, with competent lips and deficient mentolabial fold. Intraorally, the patient was in the mixed dentition stage. She had Class I molar relationship bilaterally. Severe crowding was noted in the maxillary labial segment, and there was malalignment of the mandible due to early extraction of the right and left deciduous canines. Several deciduous teeth were restored with stainless steel crowns. The permanent maxillary left lateral incisor was partially erupted. The overjet and overbite were minimum $(0.5 \mathrm{~mm})$ (Figures 1 and 2).

\section{Radiographic Examination}

A panoramic radiograph showed the presence of all permanent teeth including third molars and stainless steel crowns on four teeth (Figure 3).

\section{Diagnosis}

The patient had Class I malocclusion with severe crowding in the maxillary and mandibular arches, with minimum overbite and overjet. 

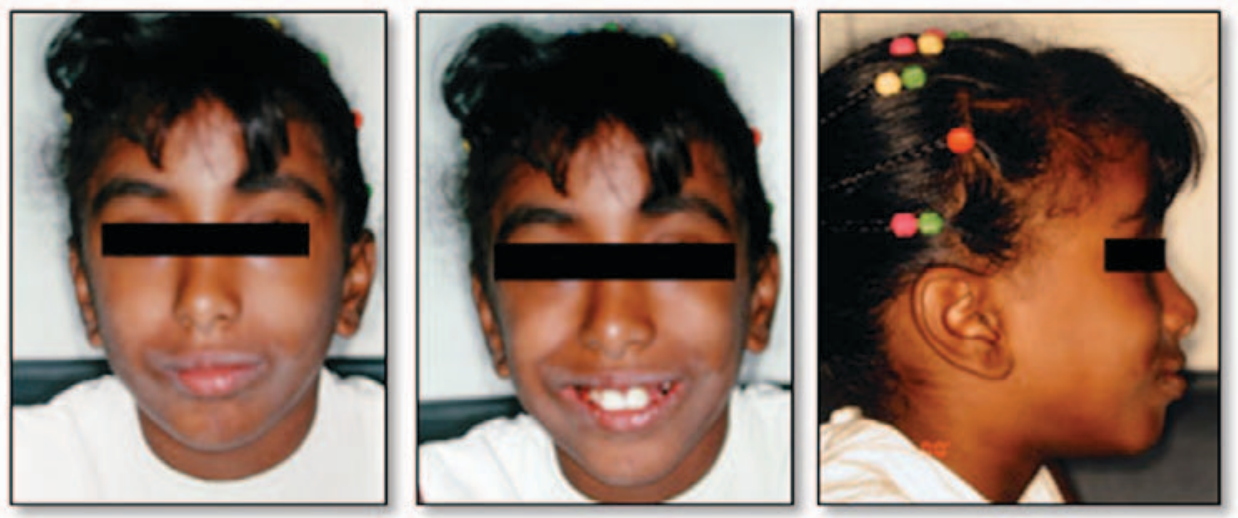

Figure 1. Pretreatment extraoral photographs.
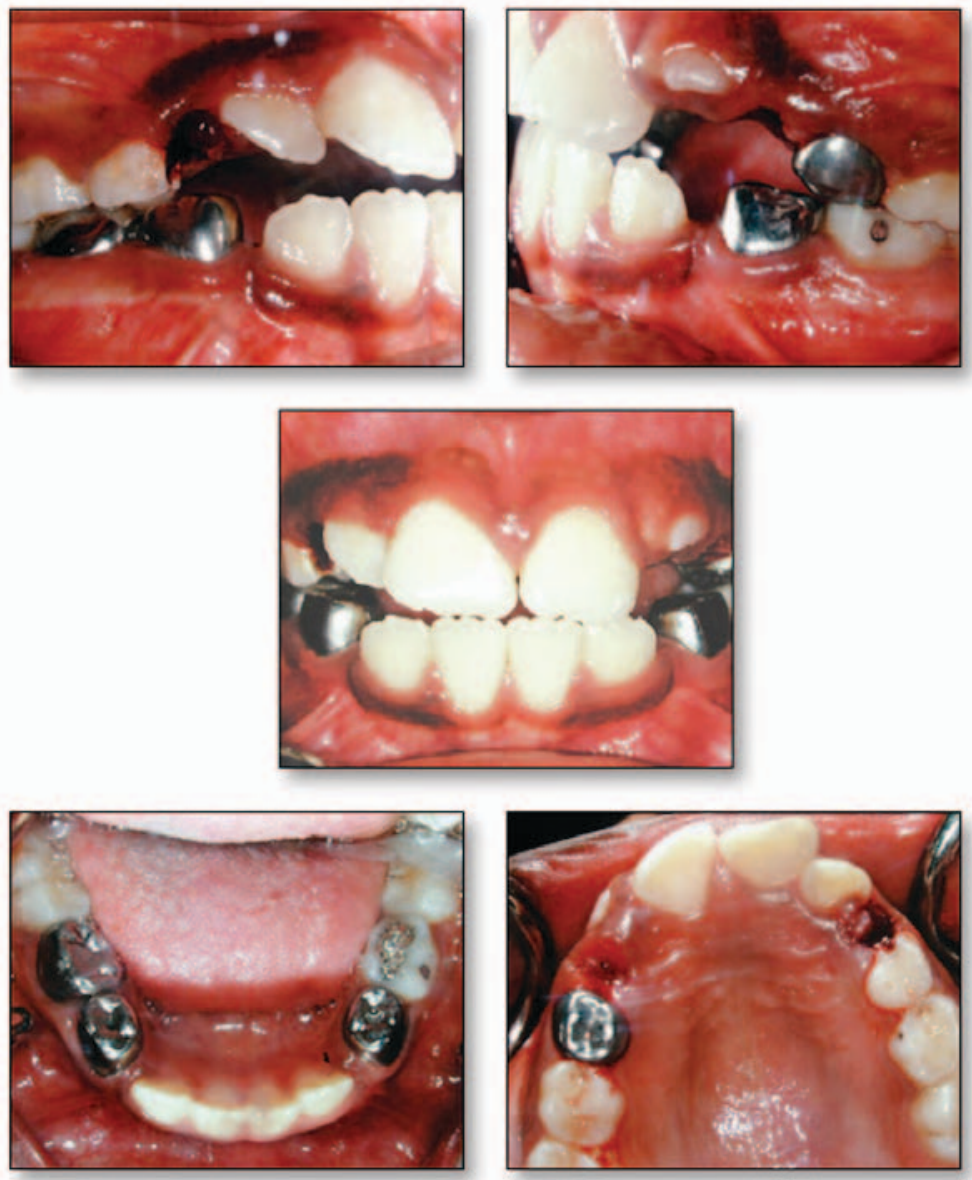

Figure 2. Pretreatment intraoral photographs showing previous extractions of the deciduous canines.

\section{Treatment Objectives}

1. To correct the crowding and better align the arches.

2. To maintain the Class I molar relationship, overjet, and overbite.

\section{Treatment}

The provided treatment included serial extractions followed by a period of fixed appliance $(0.022$ Slot) treatment to achieve improved alignment, interdigitation, and root paralleling.

The treatment of this case followed the classical serial extraction steps recommended by Kjellgren. ${ }^{1}$ 


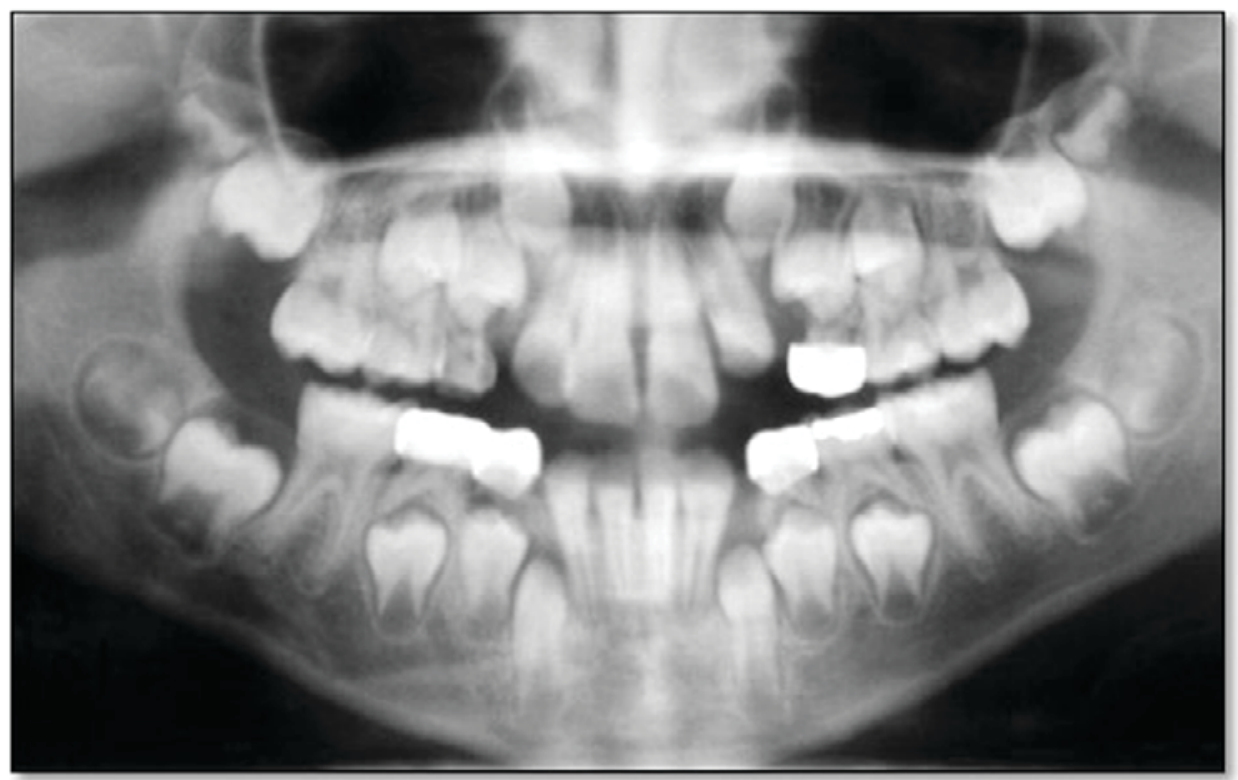

Figure 3. Pretreatment panoramic radiograph.

Step 1. Extraction of the deciduous canines. Extractions are needed to provide space for spontaneous alignment of the incisors and should be performed when the lateral incisors are half erupted (seven to eight years of age) (Figure 2).

Step 2. Extraction of the deciduous first molars. This step is needed to speed the eruption of the first premolars, when root development is halfway complete (approximately 10 to 11 years of age). It is recommended to take radiographs to assess the level of actual development (Figure 4).

Step 3. Extraction of the permanent first premolars. These extractions are needed to provide space for the permanent canines, and are performed when the eruption of the permanent canines is definitely underway, which is roughly 10 to 12 years of age (verified check on radiograph and by palpation) (Figures 5 and 6).

\section{Treatment Outcome}

Dentally, the maxillary and mandibular arches were aligned. The Class I molar and canine relationships, overjet, and overbite were maintained. Several teeth showed hypocalcification, which was attributed to the patient's poor oral hygiene. Soft tissue revealed an improvement in the naso-labial angle and reduction in the degree of convexity. The patient's smile was improved (Figures 7-9).

\section{Discussion}

The goal of orthodontic treatment is to produce a healthy, well-functioning, and stable dentition. In this respect several studies have been published on serial extractions since its inception in 1948..$^{7-10}$ A detailed discussion was provided on the topic of serial extraction for both Class I and Class II occlusion. ${ }^{11}$

For example, through the observations of Fanning ${ }^{9}$ and Gron, ${ }^{12}$ it was determined that premolars emerge when one-half to three-quarters of their roots are formed, providing useful guidelines for timing of tooth removal during serial extraction. The patient in this report was treated following the serial extractions procedure. Clearly this technique can produce good results if performed in carefully selected cases. The patient presented in this case met this basic criterion. One more important rule that was followed when performing serial extractions was the timing of the extractions. It is equally important to evaluate the case thoroughly before performing the second step, as a precaution against unpredictable developmental growth changes.

Wilson et al. ${ }^{13}$ conducted a study to assess soft tissue profile changes over time. A comparison was made between patients treated by serial extractions without subsequent orthodontic 

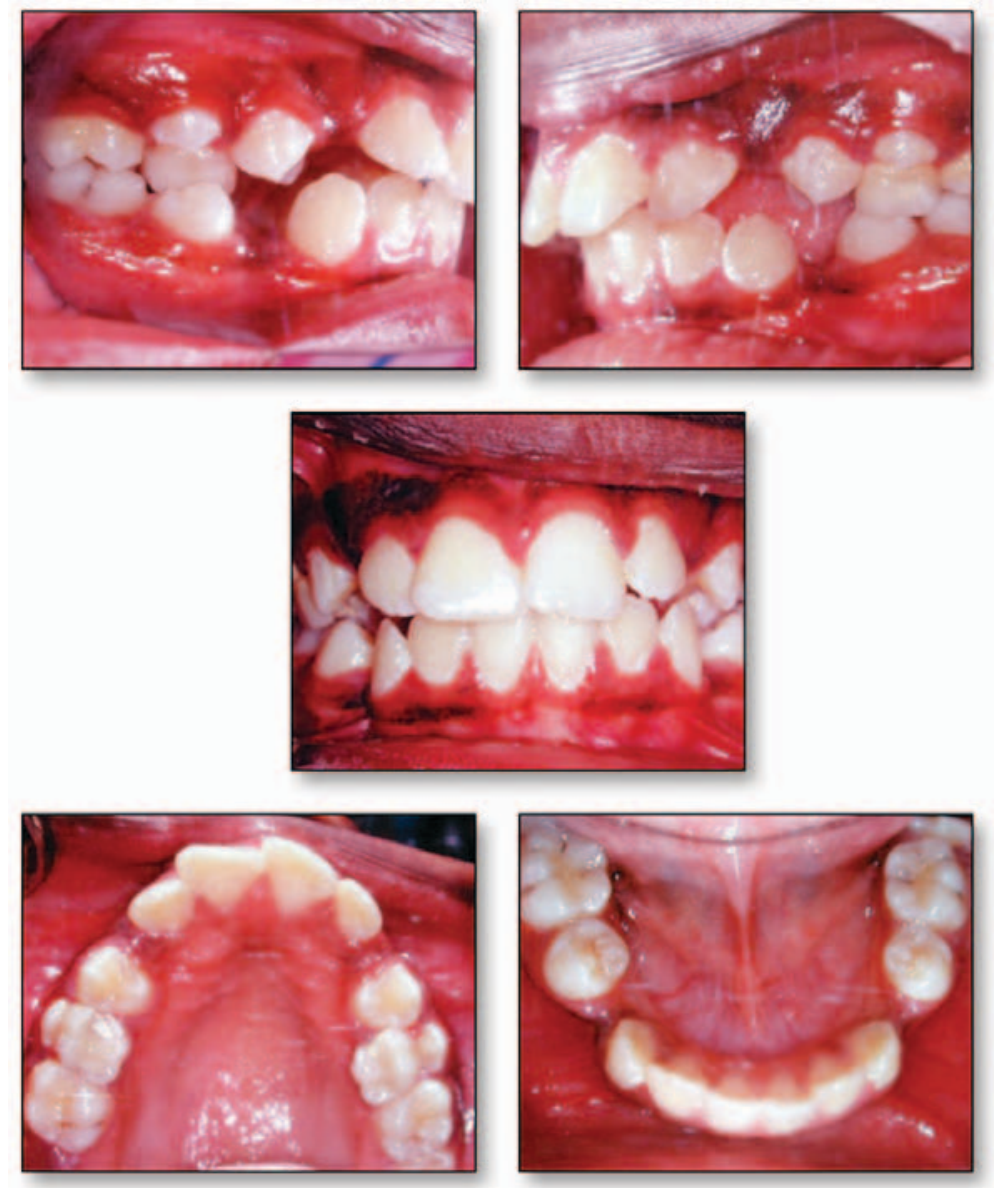

Figure 4. The deciduous first molars have been extracted.
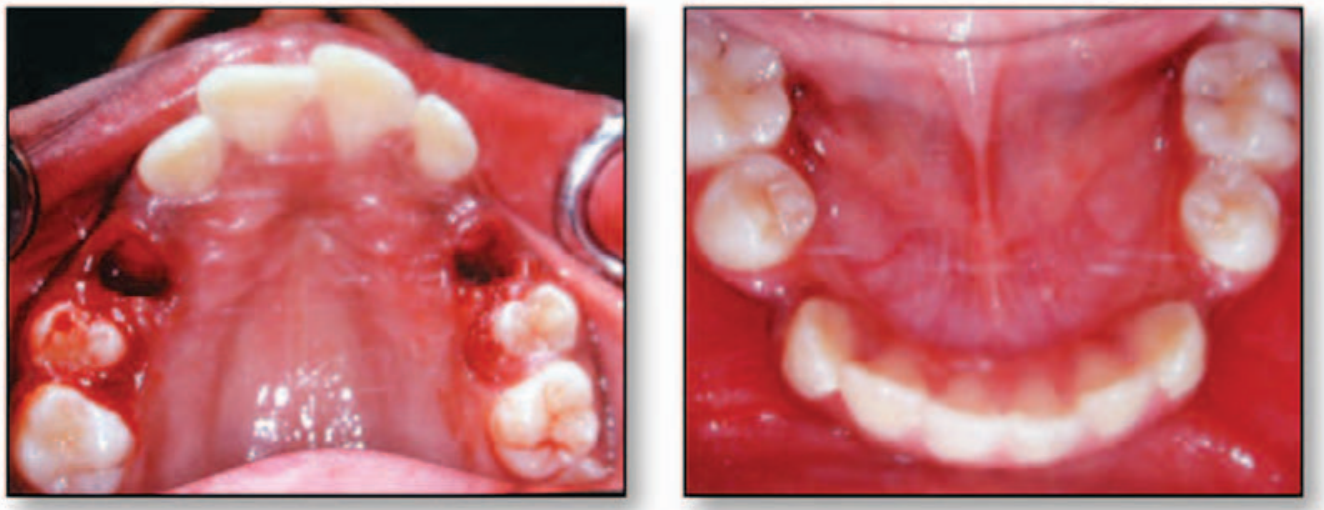

Figure 5. Extraction of maxillary and mandibular permanent premolars and extraction of deciduous maxillary second molars and eruption of permanent maxillary second premolars. The mandibular anterior segment is well aligned.

treatment $(n=28)$, patients treated with serial extraction and orthodontic treatment $(n=30)$, and patients treated orthodontically with late extraction $(n=30)$. In those patients treated with late premolar extraction, the most prominent point of the mandibular incisor after treatment became more retroclined compared to the serial extraction group. While a number of associations were noted with these variables, no significant differences were found among the soft tissue profiles of these three groups of patients. The gender differences found were most likely due to normal maturational changes, not the treatment itself. 

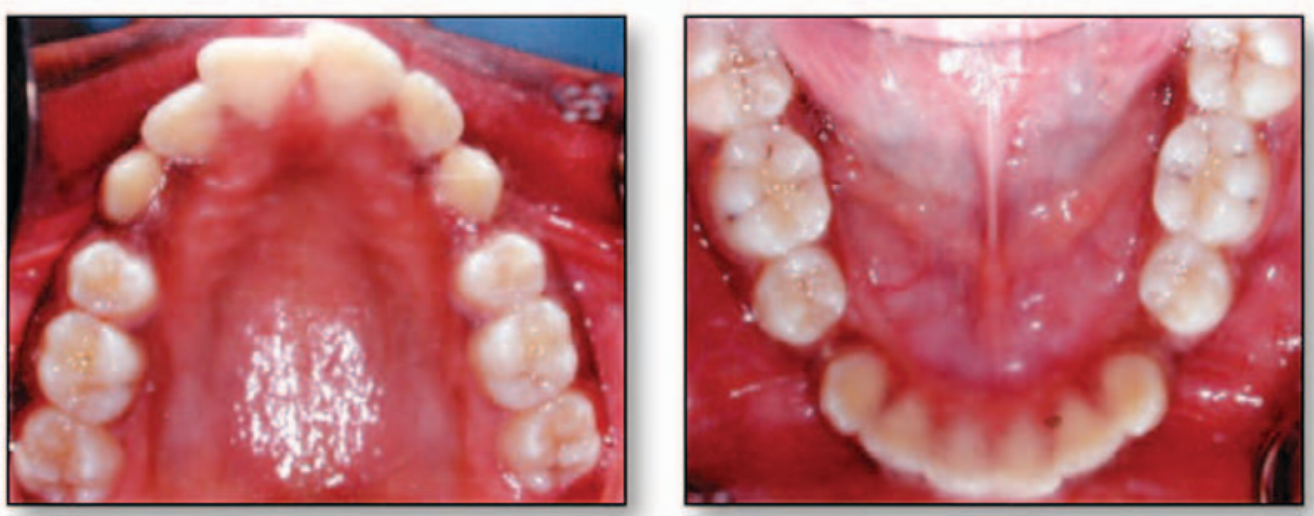

Figure 6. Eruption of maxillary permanent canines. Mandibular canines are well aligned.
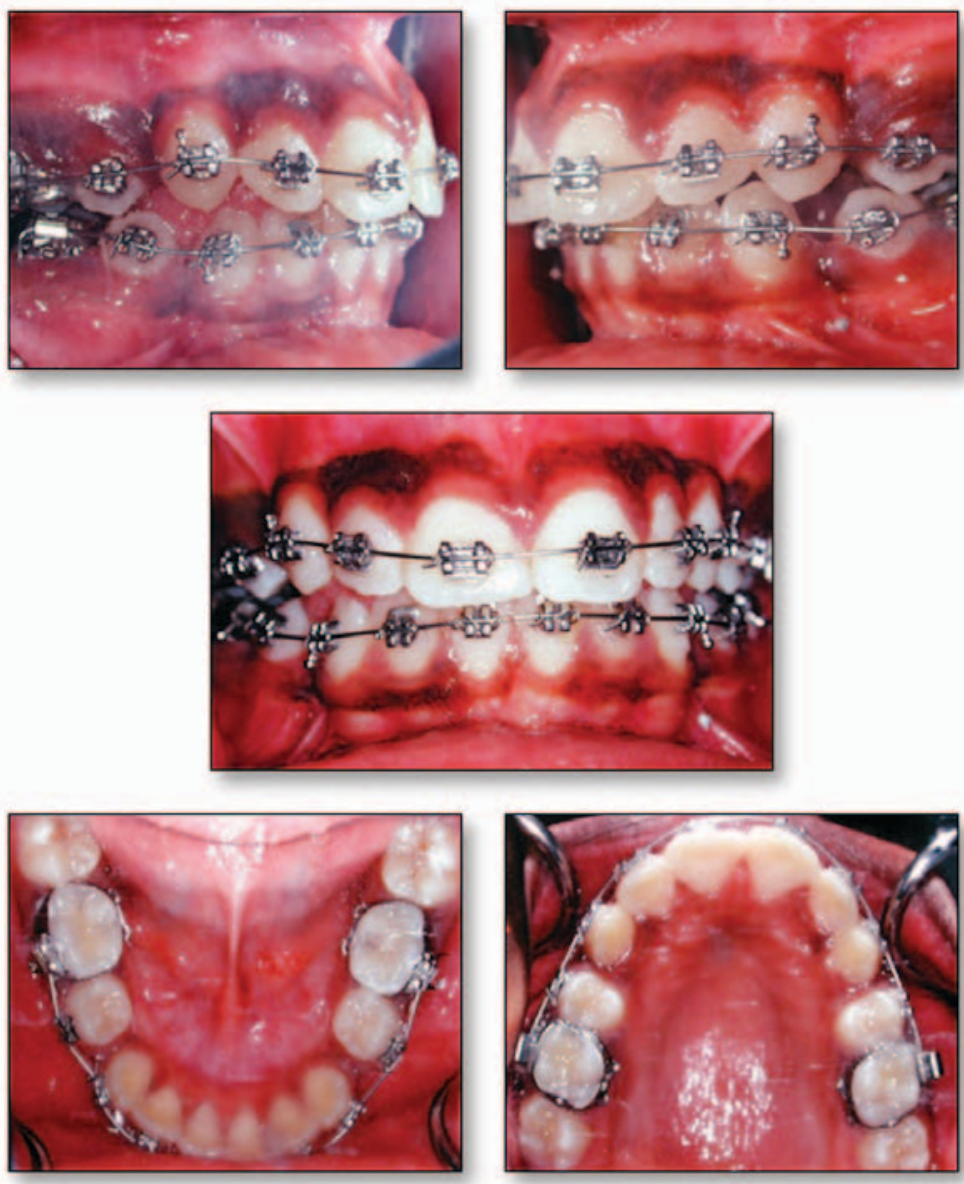

Figure 7. Fixed appliance slot 0.022. Banding the teeth in the maxillary and mandibular arches.

Serial extraction offers several advantages: (1) it permits physiologic tooth movement, (2) it reduces appliance therapy, (3) it shortens the period of retention, (4) it lessens damage to the alveolar bone and the periodontal structures, and (5) it could be used for patients with disabilities who have rejected orthodontic therapy.
On the other hand, there are several disadvantages of serial extraction: (1) increased overbite, (2) lingual tipping of the lower incisors, (3) scar tissue formation in the extraction space, (4) remaining spaces, and (5) exposure of the child to the extraction of 12 teeth. Hence, if serial extraction is not followed by fixed appliance 

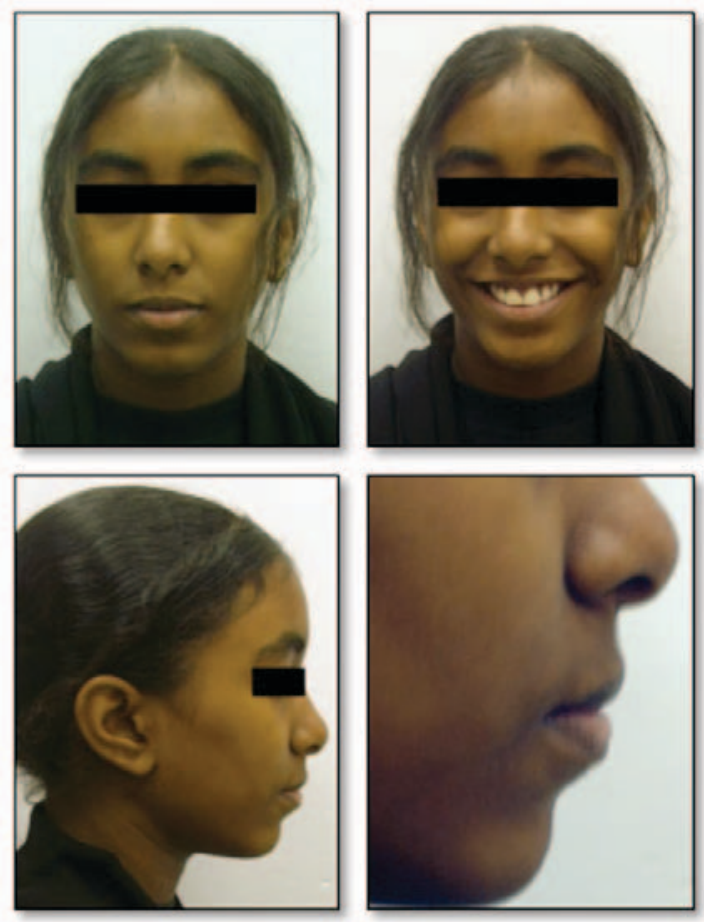

Figure 8. Frontal and lateral views of the patient after debonding.
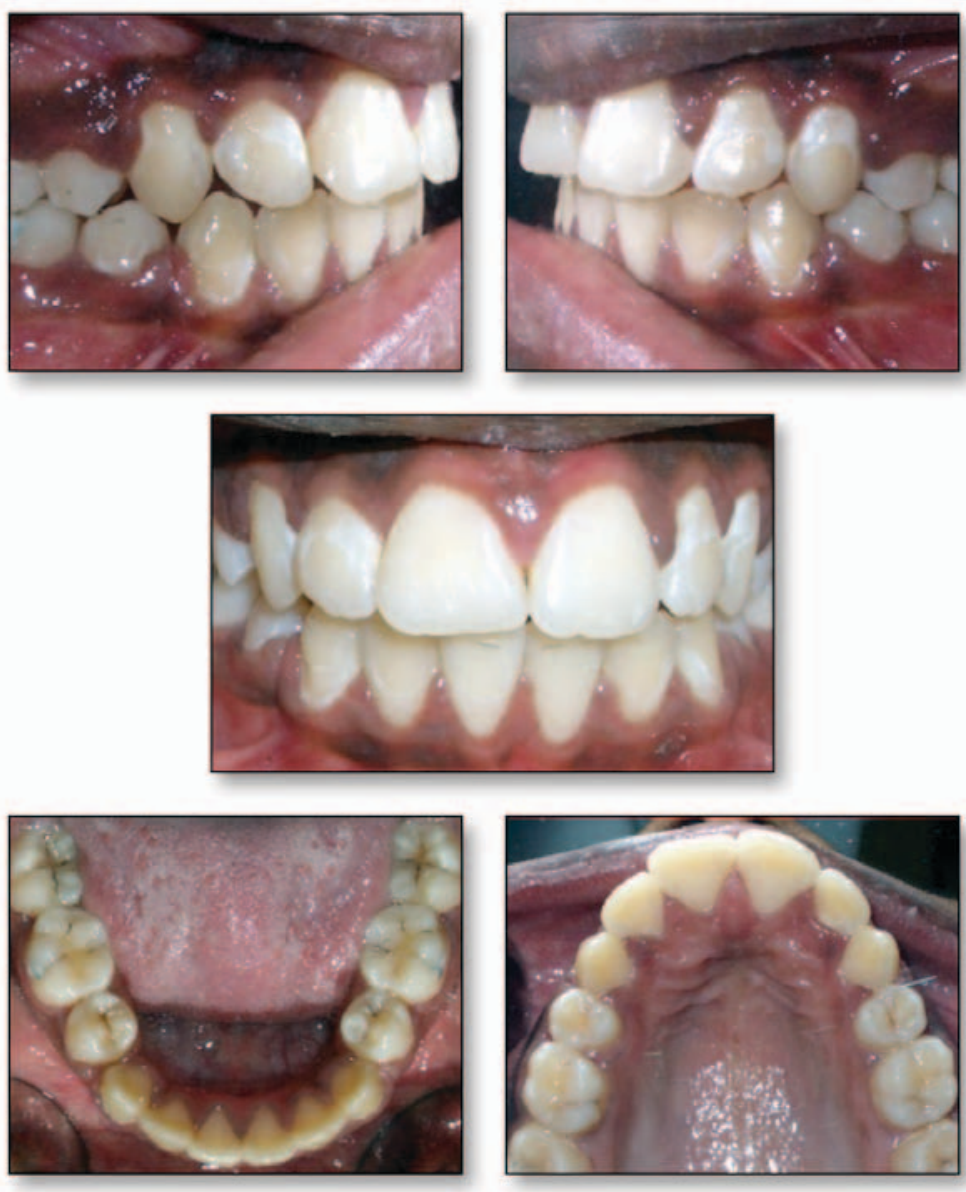

Figure 9. Intraoral views of the patient after debonding. 
therapy, ideal alignment, root positioning, overbite, and full-space closure usually are not achieved. ${ }^{14,15}$

Before performing serial extractions, gather all diagnostic records and plan for regular follow-up visits and assessment of the patient's growth and development. Be advised that the recommended timing for referring patients with moderate crowding to an orthodontist for care is in the late, mixed-dentition stage of development. Patients with severe crowding require earlier evaluation for serial extraction. ${ }^{\underline{6}}$

\section{Summary}

The general practitioner should differentiate between the classic serial extraction malocclusion and a more complex clinical situation before initiating any serial extraction treatment.

Historically, much of the criticism for the use of serial extraction was based on an inadequate diagnosis, both initially and during the three- to five-year period of observation and interceptive guidance, followed by comprehensive therapy. Contrary to this, the serial extraction approach is an efficient, noniatrogenic, and esthetically satisfying mechano-therapy that produces the best possible and most stable outcome. $\frac{5,16,17}{}$ Mayne $^{10}$ stated that diagnosis in the mixed dentition is the clinician's most challenging task and that serial extraction should be practiced only by those who can complete the treatment successfully.

\section{Clinical Significance}

This case demonstrated that despite the potential for criticism directed towards the technique, serial extraction has the potential to produce good results in carefully selected cases.

\section{References}

1. Kjellgren B. Serial extraction as a corrective procedure in dental orthopedic therapy. Acta Odontol Scand. 1948; 8(1):17-43. Also published in Trans Eur Orthod Soc. 1947/48; 1947-48:134-60. And also published in Eur J Orthod. 2007; 29(Supp 1):i37-i50.
2. Dewell BF. Serial extraction: its limitations and contraindications in orthodontic treatment. Am J Orthod. 1967; 53(12):904-21.

3. Hotz RP. Guidance of eruption versus serial extraction. Am J Orthod. 1970; 58(1):1-20.

4. Yoshihara T, Matsumoto Y, Suzuki J, Sato $\mathrm{N}$, Oguchi $\mathrm{H}$. Effect of serial extraction alone on crowding: spontaneous changes in dentition after serial extraction. Am J Orthod Dentofacial Orthop. 2000; 118(6):611-6.

5. Dale JG. Serial extraction ... nobody does that anymore! Am J Orthod Dentofacial Orthop. 2000; 117(5):564-6.

6. Ngan P, Alkire RG, Fields H Jr. Management of space problems in the primary and mixed dentitions. J Am Dent Assoc. 1999; 130(9):1330-9.

7. Dewel BF. Serial extraction in orthodontics: Indications, objectives, and treatment procedures. Am J Orthod. 1954; 40(12): 906-26.

8. Lloyd ZB. Serial extraction as a treatment procedure. Am J Orthod. 1956; 42(10):728-39.

9. Fanning EA. Effects of extraction of deciduous molars on the formation and eruption of their successors. Angle Orthod.1962; 32:44-53.

10. Mayne WR. Serial extraction-orthodontics at the crossroads. Dent Clin North Am. 1968; Jul:341-62.

11. Dale JG. Guidance of occlusion: Serial extraction. In: Graber TM, Swain BF, editors. Orthodontics: Current principles and techniques. St. Louis: Mosby; 1985. p. 259-366.

12. Gron AM. Prediction of tooth emergence. J Dent Res. 1962; 41:573-85.

13. Wilson JR, Little RM, Joondeph DR, Doppel DM. Comparison of soft tissue profile changes in serial extraction and late premolar extraction. Angle Orthod. 1999; 69(2):165-73.

14. Proffit WR, with Fields HW. Contemporary orthodontics. 2nd ed. St. Louis: Mosby; 1993. p. 399.

15. Mitchell L, editor. An introduction to orthodontics. 2nd ed. New York: Oxford University Press; 2001. p. 30.

16. Vaden JL, Kiser HE: Straight talk about extraction and nonextraction: a differential diagnostic decision. Am J Orthod Dentofacial Orthop. 1996; 109(4):445-52.

17. Bishara SE. Textbook of orthodontics. 1st ed. Philadelphia: WB Saunders; 2001. 


\section{About the Author}

Hayder A. Hashim, BDS, MSc

(Corresponding Author)

Professor and senior consultant and head of the Orthodontic Section at Hamad Medical Corporation, Doha, State of Qatar.

e-mail: hahashim78@yahoo.com 